\title{
REFORMA E QUALIDADE DA EDUCAÇÃO NO BRASIL
}

\author{
Antonio Bosco de Lima \\ Mara Rúbia Alves Marques ${ }^{\mathrm{ii}}$ \\ Sarita Medina Silva ${ }^{\text {iii }}$
}

\section{RESUMO:}

Os anos noventa do século XX foram marcados, no que se refere às políticas educacionais, pela universalização do Ensino Fundamental. Essa ocorrência se deve à centralidade da Educação Básica como princípio das orientações dos organismos internacionais. Resultou daí uma ampliação na procura do Ensino Médio e uma conseqüente pressão por ampliação da oferta da Educação Superior, com uma dimensão somente vista anteriormente nas décadas de 1960 e 1970. Esse momento histórico da educação esteve relacionado às mudanças que ocorreram nas relações do mundo do trabalho e na redefinição do papel do aparelho de Estado brasileiro. Um modelo que impulsionou novas referências para a organização da educação, influenciando o planejamento, a avaliação, a inclusão e a permanência, essencialmente, numa perspectiva quantitativa. Discutir a qualidade da educação neste modelo é o propósito deste artigo, visto ser fundamental tal reflexão tendo em vista mudanças necessárias que busquem contemplar a tão reivindicada qualidade social.

Palavras-chave: Reforma do Estado, política educacional, Educação Superior, qualidade social.

\section{REFORM AND QUALITY OF BRAZILIAN EDUCATION}

ABSTRACT: The last decade of the twentieth century was marked by the universalism of the Elementary School Teaching in what regards the educational policies. This is due to the centrality of Basic Education as a principle of the international organisms guidelines. That resulted on a demand for the Medium Level and on a consequent pressure to supply the Higher Level. This phenomenon was only experienced in the 1960s and 1970s. This historical moment of the education was related to changes occurred in the relations of the world of work and in the re-definition of the Brazilian State's role. This model has boosted new references for the education's organization, what has influenced planning, evaluation, inclusion, and permanence, essentially in a quantitative perspective. This article discusses education quality in this model once this reflection is of major concern due to the necessity of changes, which seek the so called social quality.

Key-words: State's reform; educational policy; Higher Level; social quality.

\section{Introdução}

Este texto tem como objetivo analisar os elementos da racionalidade da reforma educacional contemporânea, que se insere no contexto de ressurgimento do interesse mundial pela mudança educacional - as décadas de 1980 e 1990 do século XX -, como condição de desenvolvimento econômico, transformação cultural e solidariedade nacional, nos países centrais, e de inserção no processo global de desenvolvimento, nos países periféricos. O suposto básico é que particularmente nos anos de 1990 emergiu mundialmente uma preocupação em solucionar os déficits educacionais nos países em desenvolvimento, sendo que tal preocupação centralizou discursos em torno do controle de 
natalidade, da adequação dos sujeitos aos novos padrões e processos de trabalho e da necessária tolerância e convivência dos povos "educados", tão necessários para o novo milênio; aspectos que sintetizam os princípios e as diretrizes difundidos pelas agências internacionais.

Nesse sentido, para evidenciar a articulação entre um novo padrão de modernização ou mudança social, a reforma do Estado e a reforma educacional, destacadamente a reforma da educação superior, o presente texto é desenvolvido em três momentos que, em última instância, abordam/articulam a reforma e a qualidade da educação. Num primeiro momento, desenvolvemos os aspectos da relação entre reforma do Estado e da educação no Brasil; num segundo momento, destacamos as características centrais na reforma da educação da década de 1990 e, num terceiro momento situamos a reforma do ensino superior associada ao discurso da qualidade, porém, pautada em processos e práticas de flexibilização como marcas distintivas daquele padrão político-cultural que constitui uma nova ordem liberal e cujo cerne é a qualidade em termos, sobretudo, da equação custobenefício.

\section{Reforma do Estado e da Educação no Brasil}

O teor político para a construção de um mundo "educado", conforme os princípios e diretrizes difundidos pelas agências internacionais, entre as quais se destacam UNESCO $^{\text {iv }}$, UNICEF ${ }^{\mathrm{v}}$, PNUD ${ }^{\mathrm{vi}}$, o Banco Mundial e o Banco Interamericano de Desenvolvimento, pode ser constatado nos encontros que congregaram a "Conferência de Educação para Todos", em março de 1990, em Jomtien, Tailândia, a qual resultou, no Brasil, o "Plano Decenal de Educação para Todos", publicado em 1993. Pode ainda, ser encontrado no livro coordenado por Jacques Delors, "Educação: um tesouro a descobrir", tornado público em 1996 e, publicado no Brasil, pela primeira vez em 2001, que reúne depoimentos de pesquisadores/educadores de várias partes do mundo.

O despertar para um projeto de educação nacional consistente veio a reboque da organização mundial em torno da educação, na década de 1990. A ONU proclamou 1990 como o "Ano Internacional da Alfabetização". Ainda nesse ano, aconteceu, como já referenciamos, a Conferência Mundial de Educação para Todos, da qual resultaram os documentos "Declaração Mundial de Educação para Todos" e o "Plano de Ação para a Satisfação das Necessidades Básicas de Aprendizagem”, que apontavam os compromissos a serem assumidos pelo Estado e pela Sociedade Civil.

O Brasil só veio sistematizar tais orientações depois da "Conferencia Mundial de Educação para Todos", de 1993, na China, seguida da "Conferência de Cúpula de Nova Delhi”, na Índia em 1993. O Brasil realizou sua Conferência Nacional de Educação para Todos em 1994, em Brasília, entre 29 de agosto e 2 de setembro, com a participação e organização do $\mathrm{MEC}^{\text {vii }}$, da $\mathrm{UNDIME}^{\text {viii }}$, do $\operatorname{CONSED}^{\mathrm{ix}}$ e da $\mathrm{CNTE}^{\mathrm{x}}$, signatários do "Plano", que, em nosso entendimento, seria a gênese da LDB 9.394/96 e do nosso primeiro Plano Nacional de Educação, promulgado em 2001.

Essa Conferência resultou em um esforço para a resolução de acúmulos deficitários da educação brasileira. Os debates indicaram ser preciso canalizar o investimento da Educação Superior para a Educação Básica, responsabilizar os municípios pelo Ensino Fundamental e instituir um padrão de educação que inserisse o homem brasileiro nos meandros das novas tecnologias, habilitando-o a dialogar com elas; são ações que buscaram superar os baixos índices de escolaridade dos brasileiros. Enfim, tratava-se, na década de 1990, de tentar solucionar os problemas cumulativos de décadas anteriores, 
como as vagas reprimidas, a inadequação do fluxo escolar e os altos índices de reprovação, discrepância no financiamento da Educação Básica e da Educação Superior.

Esse movimento é marcado pela Reforma do Estado Brasileiro que, paradoxalmente irá colocar a educação como um serviço não exclusivo do Estado. Conforme podemos constatar no Plano da reforma do Estado brasileiro. Segundo a apresentação do Plano Diretor (1995) pelo então presidente da República Fernando Henrique Cardoso "a reforma do Estado passou a ser instrumento indispensável para consolidar a estabilização e assegurar o crescimento sustentado da economia” (p. 9).

Colocada desta forma a reforma tornou-se um discurso que buscou convencer a população e os chefes de governos estaduais da necessidade imprescindível de superar a crise, considerada pelo executivo federal, naquele momento, como uma crise físcal ocasionada pela incapacidade gerencial dos governos. A crise foi destacada naquele momento, como resultado do aparelho de Estado concentrar e centralizar funções, pela rigidez de procedimentos e pelo excesso de normas e regulamentos (1995), num ataque virulento a forma burocrática de administração.

Daí a necessidade de se criar uma nova forma de administração que ultrapassasse o setor público e o setor privado, a qual foi denominada pelo Plano da Reforma como o setor público não-estatal ${ }^{\mathrm{xi}}$, o qual seria responsável pela "produção de serviços competitivos ou não-exclusivos de Estado, estabelecendo-se um sistema de parceria entre o Estado e a sociedade para o seu financiamento e controle" (p. 18).

O Plano de Reforma estabeleceu como atividades exclusivas, dentre as várias elencadas, a Educação Básica e como serviços não exclusivos, dentre os vários elencados as universidades.

Essa idéia da centralidade da Educação Básica persegue o preceito de que os países que investiram na educação estariam em melhores condições econômicas; ademais, seria necessária minimamente a formação para a adequação do trabalhador ao mundo do trabalho, prevista e pautada já no século XVIII por Adam Smith (1983), e resgatado pelas novas posições liberais, cujo pressuposto seria de uma educação compensatória, mínima, para a manutenção dos meios de produção.

O argumento da centralidade da educação básica é uma proposição que se referencia a um postulado de democratização da educação, via universalização do Ensino Fundamental, no qual sabemos o que ocorreu: cerca de $98 \%$ de matrículas e os índices de aprendizagem piores que alguns países da América Latina ${ }^{\text {xii }}$. Temos, no Brasil, uma flagrante queda na qualidade do ensino, que "se expressa, principalmente, no ato de $50 \%$ dos alunos da $4^{\circ}$ série do Ensino Fundamental não saberem ler e da maioria dos que lêem, não compreender aquilo que lê." (FOGAÇA, 2006, s/p).

Essa foi a preocupação central dos educadores de vários governos, ao buscarem elementos que garantissem a ampliação e o acesso ao Ensino fundamental, incluindo mais alunos, formando mais professores, sem, entretanto, conforme atestam os vários instrumentos avaliativos, a garantia e a permanência e uma formação com primor da qualidade social.

Os dados dos testes avaliativos nacionais e internacionais têm demonstrado que o processo ensino-aprendizagem continua com sérios entreves no que diz respeito ao sucesso do ensino. É o que afirma Castro ao caracterizar a demanda reprimida de matriculas como um problema ultrapassado: "superado o desafio da inclusão devido a fundamentais políticas de universalização do acesso em anos anteriores, o governo do Estado enfrenta o problema do baixo desempenho de seus alunos, tendo como prioridade aperfeiçoar o sistema de educação" (2008, p. 3). A autora trata da realidade do Estado de São Paulo, entretanto tal análise pode ser estendida para todos os estados da federação. 
Ora, se a questão está esclarecida no tocante ao problema apresentado a sua resolução depende de um movimento global em tono da educação e do papel do Estado, problematizando-a, buscando elementos de análise, buscando a relação entre a educação Básica e a Educação Superior. Afinal, como afirma Chauí é preciso

1. Colocar-se claramente contra a exclusão como forma da relação social definida pelo neoliberalismo e pela globalização [...] 2. Definir a autonomia universitária não pelo critério dos chamados "contratos de gestão", mas pelo direito e pelo poder de definir suas normas de formação, docência e pesquisa. [...] 3. Desfazer a confusão atual entre democratização da educação superior e massificação. [...] 4. Revalorizar a docência, que foi desprestigiada e negligenciada com a chamada "avaliação da produtividade" quantitativa. [...] 5. Revalorizar a pesquisa, estabelecendo não só as condições de sua autonomia e as condições materiais de sua realização, mas também recusando a diminuição do tempo para a realização dos estrados e doutorados. [...] 6. A valorização da pesquisa nas universidades públicas exige políticas públicas de financiamento por meio de fundos públicos destinados a esse fim por intermédio de agências nacionais de incentivo à pesquisa [...] 7. Adotar uma perspectiva crítica muito clara tanto sobre a idéia de sociedade do conhecimento quanto sobre a educação permanente, tidas como idéias novas e diretrizes para a mudança da universidade pela perspectiva da modernização" (2003, p. 12-15).

Estes são elementos problematizadores que Chauí indica para a reflexão qualitativa sobre a Educação Superior. É, a partir de tais idéias, que desenvolvemos a relação entre reforma educacional e a Educação Superior, a seguir.

\section{Aspectos Centrais na Reforma da Educação na Década de 1990}

A racionalidade da reforma do Estado e uma agenda global para a educação associam o Estado, o mercado e a comunidade nos processos de regulação das políticas públicas, especialmente das políticas educacionais, no contexto do ressurgimento do interesse mundial pela mudança da administração estatal e da mudança educacional pautadas na globalização, nas novas tecnologias da informação e nos novos movimentos na sociedade civil.

A propósito, Pimenta (1998) $)^{\text {xiii }}$ tratou do processo de transformação do Estado Moderno, por meio do processo de reforma da administração pública burocrática no atual contexto das grandes tendências mundiais - a globalização, os progressos na tecnologia da informação e a emergência da sociedade civil organizada, rumo a um "novo conceito de Estado" ou à construção de um novo Estado. O sentido da análise era ressaltar o pressuposto básico de que "[...] o Estado está abandonando algumas funções e assumindo outras, o que o está levando a um novo papel, onde o setor público passa a produtor direto de bens e serviços para indutor e regulador do desenvolvimento, através da ação de um estado ágil, inovador e democrático" (1998, p. 173-174).

Segundo o autor, para desempenhar esse novo papel seria necessário reformar gerencialmente o Estado brasileiro combinando uma mistura de três instituições - o mercado (o neoliberalismo), o Estado (o estatismo) e a comunidade (o comunitarismo), com base em oito princípios (desburocratização, descentralização, transparência, accountability, ética, profissionalismo, competividade, enfoque no cidadão) e por meio de 
três estratégias para a reorganização da administração pública (privatização, publicização, terceirização).

Estes princípios e estratégias migraram facilmente da reforma do Estado para a reforma da educação e de outros setores sociais públicos, haja vista se tratar de processos e práticas de modernização da esfera estatal, mais especificamente da administração pública em geral no Brasil, com um forte sentido de rompimento com os padrões anteriores e anacrônicos de gestão do público.

De qualquer modo, reforma do Estado e reforma da educação são fenômenos político-culturais historicamente interrelacionados, embora concordemos com a premissa de que "a palavra reforma abrange diferentes conceitos ao longo do tempo, dentro do contexto dos desenvolvimentos históricos e das relações sociais" (POPKEWITZ, 1997, p. 22). O pressuposto básico é que os padrões historicamente formados compõem uma "cosmologia" que envolve o Estado moderno, as visões desenvolvimentistas da individualidade, as concepções otimistas da ciência e a intervenção da reforma planejada, associando reforma e mudança social no sentido do melhoramento e cuja análise possibilita uma "ecologia da reforma".

Considerando-se os seus padrões históricos estruturais, a reforma como política social, o Estado moderno e as ciências sociais e educacionais são práticas de governar emergentes no século XIX, ligadas aos processos de nacionalização e de formação do cidadão. Tais práticas são fenômenos modernos que articulam o governo da sociedade e o governo do indivíduo, no sentido de autogoverno. Fazem parte de "novos padrões de governança" (POPKEWITZ, 1998, p. 149), relativamente à tradição pré-moderna, que articulam o planejamento social e a administração da liberdade pelo Estado; ou as aspirações dos poderes públicos às capacidades pessoais e subjetivas dos indivíduos; ou as novas metas de bem-estar social a uma forma particular de especialização científica que deveria organizar as subjetividades.

Assim, "o saber profissional corporificava uma idéia secular peculiar ao progresso que vinculava as racionalidades políticas à construção do indivíduo" (POPKEWITZ, 1998, p. 150).

As formas históricas de pensar a mudança escolar, que influenciam as ciências educacionais e a pesquisa educacional e a política estatal para a reforma da pedagogia, contêm quatro "princípios de mudança" que funcionam como a doxa da reforma e regem os professores, os dirigentes e os alunos (POPKEWITZ, 1998, p. 147-148):

1. O discurso educacional vincula as racionalidades políticas do Estado às estratégias solucionadoras de problemas as pedagogias que regem os sujeitos/subjetividades. A profissionalização de professores e dirigentes e a formação dos alunos implicam na reconstrução da criança e na "reconstituição da identidade dos professores" (POPKEWITZ, 1998, 154), por meio de "normas de identidade" oferecidas nas reformas educacionais;

2. a idéia de progresso social ou de modernização encontra-se inscrita na pedagogia e é individualizada como "a administração social da alma" ou do self (POPKEWITZ, 1997,1998, 2000). O que implica, na pedagogia moderna, a relação entre idéia de progresso/mudança social e sua internalização pela subjetividade como mudança pessoal.

As sociedades liberais do século XIX estabeleceram uma nova relação entre o governo da sociedade e o governo, ou controle, do indivíduo. [...] A sociedade civil devia ter seus próprios padrões de regras separadas da intervenção estatal. No entanto, se o Estado devia se responsabilizar pelo bem-estar de seus cidadãos, a identidades dos indivíduos, tanto na arena 
civil, quanto na arena política, tinha de estar vinculada aos padrões administrativos encontrados na sociedade mais ampla (POPKEWITZ, 1998, p. 149). ${ }^{\text {xiv }}$

3. uma "cultura da redenção" (POPKEWITZ, 1998, p. 142), ou "cultura redentora" (POPKEWITZ, 1998, p. 147), legitima as práticas das ciências sociais e educacionais que adquirem papel ou status de produtores de mudança social e pessoal;

Enquanto nossa idéia de progresso como padrão linear de desenvolvimento é uma invenção da Renascença, as noções de desenvolvimento e progresso já se encontram no pensamento clássico. Os gregos, por exemplo, tinham uma concepção do mundo que não colocava as pessoas no centro do palco ou como eixo da sociedade ao redor da humanidade. Ao mesmo tempo em que se acreditava no desenvolvimento e no crescimento, o aperfeiçoamento social não era a base da organização da sociedade - não existia nenhuma noção de uma filosofia da mudança biológica ou aprimoramento cultural da humanidade; cada coisa vivente tinha suas próprias leis de causação, mecanismo e finalidade, sua sucessão fixa de estágios e propósito.

Com o cristianismo, os elementos da resignação e do fatalismo da atitude clássica foram alterados para os da esperança e do futuro. O tempo tornase linear e não reversível; e introduz-se um movimento dialético do nascimento até a crise, crucificação e ressurreição. Há também uma idéia de necessidade histórica. Os fatos ocorridos no passado são considerados não só como verdade pura, mas como verdade necessária (POPKEWITZ, 1998, p. 172).

O que as ciências sociais fizeram foi possibilitar a substituição da revelação religiosa (da providência divina) pela reflexão sistemática, científica (processos racionais, controlados), na busca do progresso humano - agora interpretado como projetos coletivos e sociais institucionalizados -. Exemplos da cultura redentora nas ciências sociais estão na Psicologia, na Sociologia, nos modelos fordista e taylorista da produção. E, "tal como outros projetos sociais, o treinamento de professores e a pedagogia estavam preocupados com um projeto coletivo e social" (POPKEWITZ, 1998, p. 172), que passava pela reconstrução da criança e pela mudança da identidade dos professores ("o professor profissionalizado [por meio da educação formal do professor] tinha que ser resgatado primeiro, a fim de se resgatar a criança") (POPKEWITZ, 1998, p. 154).

4. o conhecimento científico social (a pesquisa social e educacional) se funda num princípio retórico populista baseado em ideais "democráticos": promessas de autonomia, fortalecimento e emancipação.

Reconheço desde o início que as idéias sobre a cultura da redenção nas políticas e ciências educacionais são doxa; isto que dizer que, no interior do discurso atual da reforma, qualquer saber científico que não 'reinvindique ajudar', 'emancipar' e fortalecer' as pessoas que decrevem - sejam professores, crianças e, mais recentemente, os pais e as comunidades - é considerado irrazoável ou até mesmo antidemocrático (POPKEWITZ, 1998, p.148). 
Os quatro princípios acima apresentados unem crenças e agendas ideológicas aparentemente distintas (os discursos das reformas escolares sistêmicas e os discursos da pedagogia crítica ou do professor pós-moderno ou da pedagogia crítica pós-moderna, ou ainda da posição pós-moderna/marxista) em torno do "professor reformado" - o professor participativo e construtivista.

Em termos dos padrões históricos estruturais, os quatro "princípios de mudança" são resultantes de relações de poder específicos da virada do século passado, mas que representam continuidades nas reformas atuais enquanto permanência dos padrões históricos. Entretanto, tais princípios são "reembutidos" nas reformas das últimas décadas do século XX (décadas de 1980 e 1990), em termos de "mudanças dos sistemas governantes [ou dos padrões de governança] na reforma e na pesquisa educacional contemporâneas" (POPKEWITZ, 1998, p. 156), como rupturas expressas na emergência de novos conjuntos de padrões culturais.

Sinteticamente, Popkewitz (1997) destaca o conjunto dos seguintes "padrões históricos estruturais" envolvidos na reforma educacional:

1. A escola está ligada ao papel do Estado na produção de progresso;

2. a reforma está associada ao conhecimento profissional;

3. a individualização da pessoa recebe uma forma institucional específica através das práticas da pedagogia.

Em termos das reformas educacionais contemporâneas, no entanto, estes elementos "[...] fazem parte de um novo campo social - não como uma história cronológica, mas como a história das transformações das relações institucionais, do conhecimento e do poder [...]" (POPKEWITZ, 1997, p. 113).

As reformas atuais reconstituem três lugares importantes: o Estado, as ciências sociais e a pedagogia, como formas governantes. As metáforas operativas do progresso e da redenção não são mais derivadas de normas coletivas sociais, das regras comuns e das identidades fixas. Os discursos reformistas tratam de identidades múltiplas, da cooperação, da comunidade "local" e da solução flexível de problemas. (...) As identidades coletivas sociais e as normas universais corporificadas nas reformas anteriores são substituídas por imagens da identidade local, comunal e flexível (POPKEWITZ, 1998, p. 156- grifos nossos). ${ }^{\mathrm{xv}}$

Trata-se, portanto, de "novos conjuntos de padrões culturais" em meio aos quais diferentes níveis institucionais - a escola e a pedagogia, o Estado, as ciências e as universidades - têm interagido nos processos regulatórios de reforma da escola e na formação de uma nova subjetividade profissional.

Identificamos este novo campo social no que constitui o "neoliberalismo". Neste contexto as reformas - do Estado e da Educação, tendem a abarcar fortemente algumas características, quais sejam:

a) A lógica ou dialética da (des)qualificação ${ }^{x v i}$ : as reformas expressas numa recorrente busca pela qualidade por meio de "choques cíclicos e traumáticos numa espécie de "rito/recorrente" (SACRISTÁN, 1996, p. 55).

$\mathrm{Na}$ política educacional, as reformas substituem, muitas vezes, a carência de um sistema de inovação e atualização permanente, de uma política cotidiana, para melhorar as condições do sistema educacional. Desta forma, algumas reformas se seguem a outras como se fossem

Revista HISTEDBR On-line, Campinas, n. Especial, p.181-197, mai.2009 - ISSN: 1676-2584 
convulsões periódicas [...] provocando medidas reiteradas de choque (SACRISTÁN, 1996, p. 54 - grifo nosso).

b) a justificação pela busca da qualidade tem motivações: atingidas as metas de expansão quantitativa do sistema escolar a ênfase recai na qualidade das condições internas do sistema - os processos educativos, a partir da constatação dos reformadores de que os macroprojetos anteriores de reforma (anos 1960 e 1970) não atingem o cotidiano da sala se aula (SACRISTÁN, 1996, p.64 - 67). Trata-se de uma crise de qualidade tanto das práticas pedagógicas quanto da gestão administrativa, o que requer uma profunda reforma administrativa com base em parâmetros ou valores eficientistas externos ao processo educacional, associados ao mercado e utilizados pelas agências internacionais para comparar e avaliar os sistemas educacionais (GENTILI, 1996, p. 17):

[...] é necessário destacar que na perspectiva neoliberal os sistemas educacionais enfrentam, hoje, uma profunda crise de eficiência, eficácia e produtividade, mais do que uma crise de quantidade, universalização e extensão. Os sistemas educacionais contemporâneos não enfrentam [...] uma crise de democratização, mas uma crise gerencial (Grifos nossos).

c) a temática da "descentralização, participação e autonomia” (SACRISTÁN, 1996, p. 67-73): indica necessidade de mudanças na administração e na gestão do sistema escolar por meio de reordenação do poder entre as instâncias do sistema educacional, cujos aspectos fundamentais são: a redistribuição do poder de decisão e controle entre as autoridades centrais, regionais e locais; "O surgimento e reconhecimento das escolas como as verdadeiras unidades de inovação, elementos estratégicos para centrar as políticas de mudança e de reforma" (SACRISTÁN, 1996, p. 68); os movimentos e propostas que afetam a autonomia dos professores em termos de maior participação no desenvolvimento do currículo e na gestão das escolas; os movimentos de reivindicação dos pais e outros agentes sociais no controle do funcionamento das escolas.

[...] é um exemplo de como as medidas tomadas em diferentes aspectos colocam tendências que nos deixam um tanto perplexos. [...] Parece que o controle se dilui, como se desaparecesse sob a euforia democratizadora (SACRISTÁN, 1996, p. 69).

Essas tendências descentralizadoras [...] não são alheias à ascensão de um novo neoliberalismo conservador que, receoso diante de qualquer serviço público regulado pelo Estado, condena a sua intervenção na vida dos indivíduos, reclamando para esse e para toda iniciativa privada a capacidade de se auto-regular (SACRISTÁN, 1996, p. 71).

As características das reformas, apontadas acima, supõem e confirmam em síntese uma relação entre mudança social/modernização (mudanças na sociedade); reforma do Estado (mudanças na gestão pública); reforma Educacional (mudanças no sistema educativo); reforma da Escola (mudanças ou "inovações" no contexto escolar); reforma da profissão (mudanças pessoal profissional de professores e/ou gestores), sendo que a reforma e a mudança são associadas à qualificação ou à qualidade e ao melhoramento.

\section{Reforma do Ensino Superior: o discurso da qualidade}


No contexto das reformas educacionais implementadas a partir da década de noventa, a formação universitária tornou-se o foco de planos e diretrizes do modelo de políticas educacionais para os países em desenvolvimento, o que tem servido, sobretudo, de instrumento para justificar novas funções para as Instituições de Ensino Superior (IES). Exemplo disso é a LDB 9.394/96 que sugere como princípio a ser incorporado à reforma do ensino superior, a flexibilização como premissa para a qualidade da educação superior. Por decorrência da regulamentação de diretrizes para o ensino de graduação vivenciamos a implementação de uma reformulação curricular pautada nos princípios da flexibilização com vistas à formação de profissionais cujo perfil seja adequado às novas características do mundo produtivo e às demandas do mercado em constante mudança.

Vale dizer que vivenciamos a manifestação da ressignificação dos processos formativos pela integração entre políticas de reformas e "constante inovação dos planos curriculares", para se assegurarem as condições necessárias à formação de profissionais, segundo padrões de transformação do mundo produtivo atual. Noutros termos, uma formação que garanta "o desenvolvimento de habilidade para o trabalho prático, a criatividade e a capacidade para tomar iniciativa" (UNESCO, 1998 p. 22). É notório que tal recomendação revela certa fragilidade ao apelar para um pragmatismo cujas estratégias sugerem a precarização, o aligeiramento e a perda de consistência da formação.

Nesse contexto, a formação universitária constitui foco privilegiado nas políticas de reformas educacionais para o ensino superior. É possível supor, também que, o paradigma da flexibilização ao ser incorporado aos discursos e às práticas dos processos das reformas educacionais em prol da qualidade, constitui-se em proposições da política educacional para o ensino superior no Brasil. Da mesma forma, ao incorporar as noções de flexibilização e desenvolvimento de competências, as reformas fazem destas, elementos nucleares, pois segundo a ótica oficial, tais elementos devem predominar nas propostas curriculares como eixo condutor do novo paradigma da formação universitária (SILVA, 2006).

Como princípio orientador e eixo articulador das proposições oficiais a flexibilização atinge o ensino superior como pressuposto para se atingir um padrão de qualidade a ser alcançado mediante o discurso dos textos legais. Significa a substituição dos antigos currículos mínimos - aos quais o MEC atribui, dentre outras, a responsabilidade pelos baixos percentuais de diplomados e pela evasão de alunos dos cursos de graduação - considerados rígidos e ultrapassados perante as mudanças sociais e necessidades do mundo do trabalho.

Orientadas pelos padrões e realidade do mercado as reformas buscam, portanto, a eficiência, a competitividade e o bom desempenho, ou seja, a racionalidade adota, a noção de flexibilidade e a apresenta como sinônimo de inovação e, sobretudo, como liberdade e possibilidade - tal como na linguagem da área econômica. Nesse caso, flexibilizar os currículos tendo em vista o desenvolvimento de competências, ou vice-versa, conforme a concepção pedagógica dominante, seria criar estratégias para torná-los mais adequados às estruturas sociais emergentes que se configuram no processo de globalização característico do contexto histórico atual. Nesse cenário, tal tendência cumpriria importante papel quanto a criar condições para a incorporação dos pressupostos de uma pedagogia que permita flexibilizar os processos formativos e, ao mesmo tempo, garantir aos gestores das reformas a manutenção do controle sobre o produto da educação.

Se por um lado, as reformas se propõem à flexibilização, sugerindo autonomia e liberdade, por outro, tem-se um rígido controle das instituições e dos processos formativos. Como observa Dias Sobrinho a avaliação no contexto atual adquire papel preponderante, 
pois "funcionaliza as reformas" (2003 p. 98), e tem centralidade nas mudanças da educação superior. Segundo esse autor, isso é possível porque

os processos de reformas têm implícito um rígido, porém sutil sistema de avaliação com procedimentos observáveis e verificáveis. A flexibilização e a liberalização dos meios, falsos substitutos da autonomia, têm como contraponto e negação um rígido controle dos produtos finais, travestido em avaliação [...] Porém, seus resultados precisam ser objetivamente demonstrados e comparados, para efeito de medida de competitividade. (2003 p.105-106).

A conotação de avaliação associada à idéia de flexibilização se apresenta sutilmente nas indicações dos documentos do MEC e sugere um currículo flexível, estruturado por um modelo de ensino-aprendizagem por competências como parâmetro curricular orientador da formação universitária; e tais competências são entendidas como objetivos comportamentais (operacionais), conforme expressam claramente os textos oficiais. Os termos flexibilização, competência, habilidades, dentre outros, aparecem repetidamente ao longo dos documentos do MEC sobre formação universitária e são vinculados a comportamentos desejáveis a serem alcançados.

No que se refere às políticas públicas, resultantes dos arranjos macroeconômicos decorrentes do processo de reestruturação produtiva, podemos verificar a existência de um redimensionamento das políticas de reformas educacionais, especialmente no âmbito do ensino superior. Por seu turno, "é no âmbito da reforma do Estado que se pode, sob muitos aspectos, situar as estratégia e ações oficiais da reforma da educação superior no país" (SGUISSARDI e SILVA JÚNIOR, 1999 p. 27), em especial, no que se refere ao papel social das instituiçõoes educacionais, seu financiamento, sua gestão.

O padrão de modernização que orienta o atual papel do Estado mantém, assim, estreita relação com as políticas de reformas sociais, o que caracteriza as reformas que ora vivenciamos na educação superior e se expressa em todos os setores da vida social, econômica e política do país significa dizer que a reestruturação da educação superior tem se pautado, portanto, pelo ajustamento das IES públicas, a uma perspectiva gerencialista, produtivista e mercantilizadora, e pelo alinhamento às diretrizes neoliberais impostas pelas agências multilaterais, tal como nos aponta Chauí (2001); Leher (2003); Dias Sobrinho (2003). Tal padrão de modernização determina o processo de redefinição da identidade e papel das universidades; articula-se à reforma do Estado e ao processo de mudança de paradigma da administração pública, o que constitui o nó da questão do processo de reestruturação ensino superior, do que decorre, as proposições quanto a qualidade articulada à idéia de flexibilidade.

Disso depreende-se que, de acordo com os princípios da reforma do Estado, as políticas públicas passam por um processo de privatização do espaço público, e sofrem os impactos das teorias gerencialistas, próprias das empresas capitalistas imersas na lógica do mercado, que se encontram em plena expansão na perspectiva de orientar a reordenação do espaço público sob a mesma lógica do espaço privado estritamente capitalista.

Da mesma forma, a educação deve nortear-se pelo princípio da eficiência e produtividade, ou seja, expressar a "ótima relação entre qualidade e custo dos serviços colocados à disposição do público" (BRESSER PEREIRA, 1995 apud SGUISSARDI; SILVA JÚNIOR, 1999 p. 31). Assim, tal padrão acaba por reduzir a noção de qualidade e o conceito de qualidade passa a significar aumento da "quantidade de trabalhos publicados, 
pesquisas concluídas, estudantes titulados, a relação ingresso/saída, bem com a proporção alunos/docentes e tantas outras informações numéricas e estatísticas" (DIAS SOBRINHO, 2003 p.107), fazendo com que a qualidade tenha sua expressão mais exata e clara na quantificação dos produtos finais.

Dias Sobrinho (2003) ressalta que a finalidade do processo de reforma do ensino superior é flexibilizar os processos, a gestão, com o propósito de aumentar a produtividade, e ampliar a liberdade para a expansão privada. No intuito de concretizar essas propostas, as reformas têm em seu discurso o apelo à flexibilização, que é apresentada como sinônimo de ampla liberdade. Da mesma forma, a autonomia também fica reduzida à liberdade sobre os processos administrativos e financeiros, pois, "segundo a lógica do mercado e a competitividade incentivada pelos Estados, os processos têm de ser livres; tanto as instituições educacionais, como as empresas comerciais, precisam de liberdade para se estabelecer e aumentar sua eficiência e produtividade" (DIAS SOBRINHO, 2003 p.105).

Diante disso, cabe às instituições cumprir aquilo que está valorizado e determinado externamente a ela. Caberá as IES, submeter-se aos processos externos que comprovem os resultados, "tais como exames e avaliações, que funcionam como controle de qualidade, com base, sobretudo em descrições quantitativas de sua infra-estrutura e de seus produtos" (DIAS SOBRINHO, 2002 p. 20). Neste caso, pouco importa os processos que produziram tais resultados, a relevância social e as dificuldades, por exemplo. Fica evidente que, o que mais importa são os rendimentos de cada instituição e que esses possam ser comparados, permitindo a sua classificação hierarquizada, que tem como fim, ora alimentar a competitividade entre si, ora instrumentalizar o exercício de controle do governo nas tarefas de financiamento e credenciamento.

Assim, as políticas oficiais, longe de traduzir a construção da qualidade segundo critérios acadêmicos e de relevância social, fazem prevalecer os critérios mercadológicos de qualidade: as comparações, hierarquizações e competitividade, fazendo prevalecê-los sobre os critérios acadêmicos (DIAS SOBRINHO, 2002).

O Estado afasta-se da condução dos processos e das condições de criação e expansão das instituições (DIAS SOBRINHO, 2003) denominando assim, esse processo de autonomia, e fazendo com que as IES se tornem "mais livres e flexíveis para desenvolver [e oferecer] serviços e atividades que absorvam mais ajustada e facilmente as demandas do mercado" (p.105). Nesse sentido, a flexibilização é concebida "como liberalização dos processos, [e] corresponde a atual noção de autonomia, isto é, liberdade em relação aos meios" (p.105) para aumentarem sua eficiência e produtividade, ou seja, os resultados. Observa-se, então, que o valor da eficiência tende a ser central na administração pública e ao Estado caberá o controle do produto final através de mecanismos de avaliação, de tal modo que não podemos falar em autonomia, visto que esse conceito não se efetiva mediante controle.

Nesse contexto, o Estado ao controlar os resultados, em detrimento dos processos, faz com que a qualidade tenha sua expressão mais exata e clara na quantificação dos produtos finais, pois toma para si a tarefa de acompanhar, controlar e avaliar os resultados produzidos pelos serviços prestados das IES definido também os critérios e padrões de qualidade a serem perseguidos. Acrescente-se ainda que se a qualidade é representada pela quantidade dos resultados obtidos, a avaliação é tomada como controle desses produtos, já que esta concepção de avaliação está associada ao paradigma da flexibilização e à noção de eficiência, são conceitos orientados pela lógica economicista (DIAS SOBRINHO, 2003) que orienta as políticas de reformas. 
Verifica-se, portanto que a avaliação define a qualidade/eficiência da educação, através de procedimentos que focam os dados quantitativos. Esses procedimentos "transformam a avaliação numa corrida de contagem de pontos", a qual deve ainda "organizar resultados comparativos e classificatórios que informem rápida e objetivamente tanto a administração superior, em função de suas políticas de fiscalização e regulação, quanto o mercado, para efeito de orientação" (DIAS SOBRINHO, 2003, p.109) dos alunos-clientes. Ainda, de acordo com a lógica derivada do mercado, a avaliação passa a ser o "controle de qualidade", entendendo a qualidade como algo que seja medido segundo indicadores de produtividade e eficiência (DIAS SOBRINHO, 2002).

Ao ser colocada no âmbito produtivo a universidade tem novas atribuições, dentre outras, a função de fomentar e legitimar as necessidades do mercado e, nesse aspecto, compete a ela formar profissionais e gerar tecnologias e inovações que sejam colocadas a serviço da expansão do capital. Segundo analisa Chauí (2001), a universidade segundo a ótica capitalista, redefine seu padrão de qualidade para atender às necessidades do mercado, das empresas e do mundo do trabalho em mutação; subordinar seus cursos e sua produção acadêmica formal às demandas e necessidades imediatas desse mercado e do capital (LEHER, 2003).

Em decorrência disso, as universidades assumem, segundo Chauí (2001), o papel de "treinar os indivíduos a fim de que sejam produtivos para quem for contratá-los. A universidade adestra mão-de-obra e fornece força-de-trabalho" (p. 52); as IES passam a ser dotadas de caráter econômico, abrindo mão da sua função produtora de conhecimento científico e tecnológico, de seu caráter ideológico e político, em nome do alinhamento às mudanças do setor produtivo. Todas essas mudanças têm por finalidade a adequação da educação superior à economia global, que é fundamentada no paradigma da flexibilização que indica uma capacidade adaptativa a mudanças contínuas e inesperadas do mercado (CHAUÍ, 2001).

Mostra disso são as reformulações dos currículos de graduação, decorrentes do parecer 776/97 e do edital 4/97, que são fundamentadas nos conceitos de competências e empregabilidade, que objetiva uma formação profissional flexível e rápida (SILVA, 2006). Segundo Leher (2003), isso nos demonstra o claro alinhamento da educação superior brasileira às diretrizes do Banco Mundial, pois segundo esse autor a economia brasileira, no intuito de não contrariar as expectativas das agencias multilaterais, não requer cursos de graduação que prime pela produção de conhecimentos tecnológicos e científicos novos, mas de cursos onde o trabalhador possa "adquirir uma qualificação para atuar no mercado, sem precisar de um curso tradicional (mais longo)" (SCHWARTZMAN, 2002 apud LEHER, 2003 p. 92). Tal como nos mostra Schwartzman (2002) em pesquisa a serviço do Banco Mundial, "é preciso criar bons escolões de nível superior, e não grandes centros de pesquisas para todos" (p. 92), pois, os ditos "centros de pesquisas" são anacrônicos, de elevado custo e ineficientes, já que são incapazes "de atender às exigências de mercado, criando os futuros desempregados” (CHAUÍ, 2001 p. 54).

Por fim, cabe sintetizar que a reforma do Estado e, subjacente a ela a reforma do ensino superior no Brasil, resulta da sintonia entre políticas educacionais e organismos multilaterais que preconizam o mercado como portador de racionalidade econômica e, portanto, como princípio fundador e auto-regulador da sociedade. Assim, verificamos que o atual movimento da conjuntura político-econômica desempenha papel determinante do padrão de qualidade do ensino superior, em especial, da universidade pública brasileira.

Revista HISTEDBR On-line, Campinas, n. Especial, p.181-197, mai.2009 - ISSN: 1676-2584 
Podemos então reafirmar: o movimento de transformações que redefinem a identidade atual das universidades determina novas funções para o ensino superior; onde a reformulação curricular e a formação adquirem configuração e significado pragmáticos. Ao oferecer uma formação aligeirada, superficial e imediatista, como um ideal de identidade a ser construído pelo aluno futuro profissional as perspectivas que se delineiam mostram claramente a opção pelo paradigma da flexibilização neoliberal, cujo ideário ganha centralidade nas proposições do MEC; enfatiza-se uma concepção pedagógica centrada na flexibilização da formação; indica que o profissional deve ter perfil flexível e apto a responder às rápidas mudanças do setor produtivo e suprir suas necessidades. Além disso, sugere determinadas características pessoais e sociais que permitem a adequação à flexibilização de organização do mercado de trabalho assim como aos seus padrões e critérios de qualidade.

Enfim, cabe destacar que o movimento reformista educacional no Brasil explicita seu verdadeiro significado nas relações contraditórias entre sociedade, instituições de ensino e Estado no contexto da reforma do Estado. A reforma do ensino superior assume um significado histórico cuja manifestação se caracteriza e se materializa mediante ações de órgãos oficiais articuladas com orientações de agências multilaterais que assumem papel preponderante na implementação das políticas reformistas; resulta da reconfiguração do Estado em vista de seu papel no contexto de redefinição das estratégias de manutenção e expansão do capitalismo vinculado ao projeto neoliberal de minimização de seu papel social.

\section{Considerações finais: articulando reforma e qualidade}

Queremos registrar que as reformas se orientam pelo movimento de transformações globais no mundo do trabalho, o qual orienta urgentes mudanças sociais globais, fundamentadas nos princípios neoliberais. Os processos de mudança educacional norteiam as políticas educacionais em curso no cenário mundial, sobretudo na América Latina, em um contexto de ressignificação de paradigmas e de modernização das IES e da formação profissional.

É possível perceber que os paradigmas que orientam a reforma educacional em geral, e do ensino superior em particular ao pretender transformar as IES em instituição flexível geradora de maior competitividade e lucratividade, a reforma se justifica como política estratégica do MEC que articula as reformas na educação às rápidas mudanças do mercado e do setor produtivo. A flexibilização do currículo constitui importante mediador na relação entre qualidade, formação e mercado. Justificam-se, assim, os processo de flexibilização institucional e curricular coerentes com o projeto de expansão e reconfiguração institucional de caráter mercadológico, que a universidade ora vivencia.

Desta análise, destacamos como elementos de transformação que, em primeiro lugar, a lógica da Educação não pode estar pautada na equação custo-benefício, esta é uma lógica empresarial, mercadológica, admissível para o planejamento de mercadorias, não da elaboração e transmissão do conhecimento, objetivo essencial da educação.

Em segundo lugar, que a educação carece de universalização e democratização, ou seja, uma relação entre a forma quantitativa e a qualidade. Incluir sim, mas garantir a permanência, buscando a implementação da qualidade social, cuja concepção está "estreitamente vinculada ao combate às desigualdades. Às dominações e às injustiças de qualquer tipo" (SILVA, 1996, p. 170). 
Isso, não é impossível, pois temos exemplos mundiais de investimento na educação, que criaram sistemas nacionais de educação e que caminharam na resolução de seus problemas a partir de investimento na educação, eliminando o analfabetismo e impingindo um padrão de qualidade-social para os alunos. Precisamos superar a equação custobenefício, tão em voga no Brasil dos anos 1990.

\section{Referências}

APP-SINDICATO. LDB. Lei de Diretrizes e Bases da Educação Nacional. Lei 9.394/96. Curitiba: APP-Sindicato, 1997.

BRASIL. Edital 4. Publicado em 4/12/1997. Reforma Curricular dos Cursos de Graduação. Brasília: — SESU/MEC, 1997a.

Parecer CNE/CES n. 776/97, de 3/12/97. Brasília: Câmara de Educação Superior/CNE/MEC, 1997b.

Lei no 9.394, de 20 de dezembro de 1996. Estabelece Diretrizes e Bases da Educação NACIONAL. Diário Oficial da União, Brasília, 1996.

Ministério da Administração Federal e da Reforma do Estado. Plano Diretor da reforma do aparelho do Estado. Aprovado pela Câmara da Reforma do Estado em 21 de setembro de 1995. Brasília: Presidência da República, 1995.

Plano Decenal de Educação Para Todos. Brasília MEC, 1993.

CASTRO, M. H. G. de. O mérito do professor. In: Folha de São Paulo. Opinião. P. 3. 15 de outubro. São Paulo: Folha de São Paulo, 2008.

CHAUI, M. A universidade pública sob nova perspectiva. In: Revista Brasileira de Educação. Set/out/Nov/dez, de 2003. Campinas, SP: Autores Associados, 2003.

Escritos sobre a universidade. São Paulo: Editora da UNESP, 2001.

DELORS, J. Os quatro pilares da educação. In: Educação: um tesouro a descobrir. Relatório para a UNESCO da Comissão Internacional sobre Educação para o século XXI. São Paulo: Cortez; Brasília, DF: MEC: UNESCO, 2001.

DiAS SoBRINHO, J. Quase-mercado, quase-educação, quase-qualidade. Raies Avaliação. Revista da Rede de Avaliação Institucional da Educação Superior. Campinas: 2002: 9-33.

. Educação superior: flexibilização e regulação ou avaliação e sentido público. In: Dourado, L. F.; CAtani, A. M.; Oliveira, J. F. (Org.). Políticas e gestão da educação superior - transformações recentes e debates atuais. São Paulo: Xamã, 2003: 97-135.

FOGAÇA, A. Educação, trabalho e desenvolvimento tecnológico no Brasil: um breve retrospecto dos últimos dez anos. Seminário de comemoração dos 50 anos do DIEESE. São Paulo, maio de 2006. MIMEO. 
GENTILI, P. Neoliberalismo e educação: manual do usuário. In: Escola S. A.: quem ganha e quem perde no mercado educacional do neoliberalismo. Brasília: CNTE/confederação Nacional dos Trabalhadores em Educação, 1996, p. 9-49.

LEHER, R. Expansão privada do ensino superior e heteronomia cultural: um difícil início de século. In: DOURADO, L. F.; CATANI, A. M.; OLIVEIRA, J. F. (Orgs.). Políticas e gestão da educação superior: transformações recentes e debates atuais. São Paulo: Xamã; Goiânia: Alternativa, 2003.

MARQUES, M. R. A. A Reforma educacional em Minas Gerais nos anos 80 e 90: a dialética da (des)qualificação. Revista Brasileira de Política e Administração da Educação/RBPAE. Porto Alegre: ANPAE, v. 17, n. 2, jul./dez. 2001 (Publicado em 2003).

Um fino tecido de muitos fios... mudança social e reforma educacional em Minas Gerais. Piracicaba-SP, Universidade Metodista de Piracicaba/UNIMEP, 2000. Tese de Doutorado.

PEREIRA, L. C. B. e GRAU, N. C. (Org.). O público não-estatal na reforma do Estado. Rio de Janeiro: FGV, 1999.

PIMENTA, C. C. A reforma gerencial do Estado brasileiro no contexto das grandes tendências mundiais. In: Revista de Administração Pública, Rio de Janeiro, 32 (5), set./out. 1998, p. 173-199.

POPKEWITZ, T. S. Trad. Beatriz Afonso Neves. Reforma educacional: uma política sociológica - poder e conhecimento em educação. Porto Alegre: Artes Médicas, 1997.

Trad. Ernani Rosa. 2 ed. Reforma, conhecimento pedagógico e administração social da individualidade: a educação escolar como efeito do poder. In: IBERNÓN, F. (Org.). A educação no século XXI - os desafios do futuro imediato. Porto alegre: Artmed, 2000, p.141-169.

Trad. Luiz Ramires. A administração da liberdade: a cultura redentora das ciências educacionais. In: WARDE, M. J. Novas políticas educacionais: críticas e perspectivas. São Paulo: PUC, 1998. p. 147-172.

Trad. Tomaz Tadeu da Silva. História do currículo, regulação social e poder. In: SILVA, T. T. da. O sujeito da educação - estudos foucaultianos. Petrópolis: Vozes, 1994, p.173-210.

SACRISTÁN, J. G. Reformas educacionais: utopia, retórica e prática. In: SILVA, T. T. da; GENTILI, P. Escola S. A.: quem ganha e quem perde no mercado educacional do neoliberalismo. Brasília: CNTE/confederação Nacional dos Trabalhadores em Educação, 1996, p. $50-74$.

SGUISSARDI, V. e SILVA JÚNIOR, J. dos R. Novas faces da educação superior no Brasil: reforma do Estado e mudança na produção. Bragança Paulista: EDUSF, 1999. 
SILVA, S. M. Diretrizes Curriculares Nacionais e a formação de professores: flexibilização e autonomia. Tese 2006 (Doutorado em Educação) - Universidade Estadual de Campinas, Campinas, 2006.

SILVA, T. T. da. O projeto educacional da nova direita e a retórica da qualidade total. In: SILVA, T. T. da e GENTILI, P. Escola S. A.: quem ganha e quem perde no mercado educacional do neoliberalismo. Brasília, DF: CNTE, 1996.

SMITH, A. Artigo II. In: A riqueza das nações: investigação sobre a sua natureza e suas causas. Volume II. São Paulo: Abril Cultural, 1983.

UNESCO. ORGANIZAÇÃO DAS NAÇÕES UNIDAS PARA A EDUCAÇÃO, A CIÊNCIA E A CULTURA. Declaração Mundial sobre Educação Superior - Declaração Mundial sobre Educação Superior no século XXI: visão e ação. Paris, 1998.

\footnotetext{
${ }^{\mathrm{i}}$ Doutor em Educação pela PUC/SP. Professor da Faculdade de Educação da Universidade Federal de Uberlândia/UFU. Coordenador do Grupo de Pesquisa Estado, Democracia e Educação (GPEDE). Email: bosdag@terra.com.br. [Doctor in Education - PUC/SP. Professor of the Faculty of Education - Federal University at Uberlândia/UFU. Coordinator of the Research Group 'State, Democracy and Education' (GPEDE). Email: bosdag@terra.com.br].

ii Doutora em Educação pela UNIMEP/SP. Professora da Faculdade de Educação/FACED da Universidade Federal de Uberlândia/UFU. Membro do Grupo de Pesquisa Pólis. Email: mara@ufu.br. [Doctor in Education - UNIMEP/SP. Professor of the Faculty of Education/FACED - Federal University at Uberlândia/UFU. Member of Research Group Pólis. Email: mara@ufu.br].

iii Doutora em Educação pela UNICAMP/SP. Professora da Faculdade de Educação da Universidade Federal de Uberlândia/UFU. Coordenadora do Núcleo Políticas e Gestão da Educação. Membro dos Grupos de Pesquisa GPEDE e Pólis. Email: sarita@ufu.br. [Doctor in Education - UNICAMP/SP. Professor of the Faculty of Education - Federal University at Uberlândia/UFU. Coordinator of the 'Center of Education Policies and Management’. Member of Research Groups GPEDE and Pólis. Email: sarita@ufu.br].

${ }^{\text {iv }}$ Organização das Nações Unidas para a Educação, a Ciência e a Cultura.

${ }^{\vee}$ Fundo das Nações Unidas para a Infância.

${ }^{\text {vi }}$ Programa das Nações Unidas para o Desenvolvimento.

vii Ministério da Educação.

viii União Nacional dos Dirigentes Municipais da Educação.

${ }^{\text {ix }}$ Conselho Nacional dos Secretários de Educação.

${ }^{x}$ Confederação Nacional dos Trabalhadores em Educação.

xi Público não-estatal "são organizações ou formas de controle 'públicas' porque voltadas ao interesse geral; são 'não-estatais' porque não fazem parte do aparato do Estado, seja por não utilizarem servidores públicos, seja por não coincidirem com os agentes políticos tradicionais" (PEREIRA e GRAU, 1999, p. 16) (Grifos dos autores).

xii O Brasil possui o mais elevado índice de repetência da América Latina e, segundo a Unesco, no Índice de Desenvolvimento Educacional, entre 121 países está na $71^{\text {a }}$ posição.

xiii Administrador formado pela FGV-SP, à época ligado ao Programa de Modernização do Poder Executivo Federal do MARE, financiado pelo Banco Interamericano de desenvolvimento (BID).

xiv Popkewitz afirma trata-se da constituição ou "produção de uma mentalidade através da qual o novo cidadão/indivíduo agia e participava, aquilo que Norbert Elias chamou de 'o processo civilizatório' e Foucault de 'governamentalidade"', com a ressalva de que, embora haja distinções entre os arrazoados de Elias e Foucault, "cada um deles aponta como a maneira de governar as disposições, as sensibilidades e as consciências do indivíduo tornou-se um problema da modernidade" (1998, p. 149-172).

${ }^{x v}$ Em Popkewitz (1994, p. 186) o conceito de "pedagogia" é identificado com currículo. Já em Popkewitz (1998, p. 159) é identificado com escolarização.
} 
xvi A propósito, consultar Marques (2000, 2001). A dialética da (des)qualificação é relacionada ao mal-estar cultural, institucional e profissional uma vez que o suposto da qualidade ou da qualificação tende ao esvaziamento da história, da cultura ou das experiências acumuladas, cujo efeito é o da tábula rasa, ou seja, a sensação de estar começando sempre do ponto zero rumo a soluções racionais interpretadas como panacéias universais. Nesse contexto justifica-se o apelo ao consenso público, proporcional à proliferação de propostas reformistas cuja linguagem é tanto mais velha quanto mais ressignificada. Daí o entendimento da reforma educacional como mobilização e administração públicas para um determinado padrão de modernização ou mudança social e para um determinado padrão administrativo do Estado. É a identificação da dialética da (des)qualificação na reforma educacional que possibilita a decomposição e recomposição de elementos recorrentes na prática social reformista: elementos de continuidade, conforme os padrões históricos estruturais; elementos de ruptura, conforme as variações históricas superestruturais; e elementos de síntese entre as reformas, os quais operam no campo simbólico-cultural, a despeito dos padrões e das variações superestruturais da modernização.

Artigo recebido em: 05/11/2008

Aprovado para publicação em: 20/11/2008 